\title{
A Literature-Based Approach on Age Factors in Second Language Acquisition: Children, Adolescents, and Adults
}

\author{
Burhan Ozfidan $^{1,2}$ \& Lynn M. Burlbaw ${ }^{1}$ \\ ${ }^{1}$ College of Education, Texas A\&M University, College Station, USA \\ ${ }^{2}$ College of Humanities, Prince Sultan University, Riyadh, Saudi Arabia \\ Correspondence: Burhan Ozfidan, College of Education, Texas A\&M University, College Station, USA; College \\ of Humanities, Prince Sultan University, Riyadh, Saudi Arabia.
}

Received: October 8, 2018

doi:10.5539/ies.v12n10p27
Accepted: September 25, 2019

Online Published: September 29, 2019

URL: https://doi.org/10.5539/ies.v12n10p27

\begin{abstract}
Age is an essential factor in Second Language Acquisition (SLA), impacting the success of students and instructional methods. The purpose of this study is to examine the age factor in SLA by examining three age categories - children, adolescents and adults. In doing so, the study considers the Critical Period Hypothesis as a base of linguistic research in the area of age factor. The study disapproves the assertion of the hypothesis that all prepubescent learners are able to acquire native-like proficiency in target language pronunciation. The study analyzes common SLA beliefs, including: 1) younger learners are more successful than older learners, 2) the language learning processes of younger learners are less stressful and require less of an effort, and 3) young learners are more skillful in language learning. Adolescents and adults are considered as older learners in terms of cognitive maturity. The results of the study indicated that children learn a language easier than adolescents and adults, particularly with respect to pronunciation and morpho syntax. Adolescents are good at syntax and listening sills, while the best results for adults are for reading and writing activities. Thus, the types of brain organization at learners of different developmental stages lead to the need for a diversity of instructional methods for children, adolescents and adults.
\end{abstract}

Keywords: SLA, age, children, adolescents, adults

\section{Introduction}

The age factor has been a concern of debate in second language acquisition studies for several decades. Researchers have examined different questions - how young and older learners differ in the language learning process, which instructions are the most beneficial for certain age categories, which age category of learners demonstrates the highest success, and others (Aydin \& Ozfidan, 2014; Aydin \& Koc, 2012; Spinner \& Gass, 2019). The literature includes investigations of the age factor, which consider the age of students, the learning environment, and the exposure to the target language.

After briefly revisiting factors that can influence second language acquisition, such as motivation, cognition, experience, and native language, the study considers the Critical Period Hypothesis (CHP), which is based on the structure of brain and neurological changes (Vygotsky, 1962). These defining features help to justify discrepancy between prepubescent and pubescent learners in terms of language accomplishment. Adherents of CHP believe that native-like pronunciation is unobtainable after someone has reached the age of puberty. However, numeral discords have occurred recently (Hyland, 2019; Ugurlu \& Ozfidan, 2015).

Additionally, this study examines second language acquisition assumptions. The first assumption is that younger beginners outperform older learners. However, insufficient affective stability and cognitive abilities may prevent children from understanding early language learning instructions (Vygotsky, 1986). The second assumption is that young learners do not experience a sense of frustration. However, the instructional environment and techniques have been found to have great importance on the frustration levels of learners of different age categories. The third assumption is that young learners are more skillful than older learners. However, empirical research has disproven this (Zafar \& Meenakshi, 2012).

Appropriate instructional methods for children, adolescents and adults are different because of experience, cognitive abilities and maturity. The current study asserts that learners do not differ merely by age but also by 
different cultural and linguistic backgrounds. Regardless, learners of all ages benefit from interactions with the physical world and people (Zhang, 2009).

Even though children have certain advantages over older learners, their achievements may be decreased in a formal learning environment. Children greatly benefit from an authentic target language environment, sensorimotor activities and colorful instructional materials. The crucial point at this period of time is vocabulary growth (Andrews, 2017).

Young learners have significant differences from older learners, who are adolescents and adults. Older learners are cognitively mature, which deprives them of natural, or subconscious, way of language acquisition. They benefit from formal settings with clear instructions and explicit rules (K. Hyland \& F. Hyland, 2019). Researchers claim that older learners outperform young learners in academic achievement, with the exception of pronunciation (Spinner \& Gass, 2019). Adolescents benefit from repetition and memorization, and display relatively low results in public activities. Adults are more organized, self-motivated and responsible, which makes the teaching process easier (Ziglari \& Ozfidan, 2016). They profit from a cooperative environment and formal instructions.

All things considered, this study posits that every age is suitable for language learning and that certain advantages and drawbacks may be observed in the process of language learning of children, adolescents and adults.

This study considers these questions related to age factors in second language acquisition:

1) Are young learners more sucessfull than older learners?

2) Which methods are the most beneficial in second language acquisition for children, adolescents and adults?

3) Which age is the most successful for second language acquisition?

This study considers the age factor and its relationship with second language acquisition. It examines three age categories, which are children, adolescents, and adults. Scientists generally mark three age categories of a language learner: children (till puberty), adolescents (after puberty till 19), and adults (after 19) (Hyland, 2019; Spinner \& Gass, 2019).

First of all, the researchers give a general background of factors that affect SLA. Next, Critical Period Hypothesis is described. Afterwards, the common SLA assumption, which is the younger, the better is considered. Next, the instructional methods for students of different age categories are addressed. At the end of the study, the question of which age category is better to begin SLA is considered.

\section{Factors That Affect Second Language Acquisition}

Second Language Acquisition (SLA) is the acquisition of a language, after knowledge of a mother tongue is formed. Second language (L2) related to a language that is commonly used in the country of learner's residence. The primary target in study of SLA is an examination of factors that influence language learning (LL).

SLA is affected by a vast number of internal and external factors, which may have both negative and positive effects. Among the most substantial internal factors are age, personality (extroversion and introversion), experiences, cognition (learning style), motivation (instrumental and integrative), and native language (L1), aptitudes. External factors are curriculum, classroom instruction and materials, culture, socioeconomic status, access to communication with native speakers (Andrews, 2017). In other words, the interconnection of social, affective, psychological and cognitive factors influences competence and performance in SLA.

\section{The Critical Period Hypothesis}

This hypothesis is based on the structure of the brain. Neurological changes are a defining feature of the brain, and adherents of CHP say that the plasticity of cortex makes children superior to in adults in some respects. Therefore, children and adults differ in the way in which their brains learn a language, and, with this in mind, CHP presents itself as a convincing theory. Shakouri and Saligheh (2012) emphasized that age greatly impacts phonology, and Zhang (2009) and Munoz et al. (2010) believe that children demonstrate better performance in pronunciation than adults do,

Brain flexibility that is observed in early teens permits children to acquire native-like pronunciation, but this ability rapidly declines after puberty. The belief is that after a person has reached maturity, acquiring native fluency in L2 becomes unattainable. As a result, older learners develop a "foreign accent". Zafar and Meenakshi (2012) said that self-consciousness, which increases with age, impedes learners from using language skills fully, especially communicatively. They also claimed that "some older learners can achieve native-like proficiency, 
although they definitely constitute a minority of second language learners" (p. 640). Nevertheless, Kerswill (1996) emphasized that people can modify their pronunciation during their lifespans. He noted that "speakers copy new pronunciations of individual words during their lifetime - for example, to avoid social stigma" ( $\mathrm{p}$. 169).

In recent years, disagreements on the $\mathrm{CPH}$ have grown rapidly, and various factors that impede prepubescent learners from acquiring native-like pronunciation have been found. Those factors are insufficient exposure to the target language, inappropriate instructional environment, interference with L1 and the predominance of L1, and others. Archila-Suerte et al. (2012) stated that "that the prolonged use of a native language (a) interferes with accurate L2 learning or (b) decreases the number of opportunities for input and output of L2" (p. 199). Additionally, Archila-Suerte et al. (2012) answered the question of why some early bilinguals have foreign accents. They explained that the reason for the lack of a native-like fluency and accuracy in pronunciation was the prevalent use of a child's L1. This usage may cause decrease of L2 learning and decrease of input and output of the target language.

\section{Common SLA Bias: The Younger-The Better}

The most common question among linguists who have examined the age factor in SLA is that of young learners vs. older learners. McLaughlin (1992) et al. stated that this belief that younger learners are more successful has led to the formation of a SLA bias. Scientists have made great efforts and provided empirical evidence to eliminate this prejudice. McLaughlin has asserted that knowing about the process of SLA in children is vital. He also affirmed that the subconscious suppositions of teachers about language learning and improbable expectations with respect to the progress of children are often false and cause a decline in the teaching-learning process. In a study, Nikolov and Djigunovic (2006) claimed that not every child displays readiness for learning a language at the age of 6 because a child lacks specific cognitive abilities and are not affectively stable.

One more misconception is that of frustration that can arise during the process of language learning. Despite the common feeling that children learn effortlessly, McLaughlin (1992) says that children experience difficulties, too. In a study, Shakuori and Saligheh (2012) suggest that "we must avoid the danger of creating a dichotomy between the younger-the better and the older-the better" (p. 3). Anxiety related to LL is not the same for children who have different cultural backgrounds. Learners from particular cultural backgrounds may feel nervous when a teacher asks them to answer a question or to perform an activity independently. According to McLaughlin (1992), controlled conditions are crucial in SLA. In an instructional environment that satisfies the requirements of learners and fits their current level of knowledge, adolescents and adults achieve better success. McLaughlin gives strong evident, refuting the illusion that "children learn language faster than adults" (p. x). He asserts that the quantity of knowledge required for communication differs between children and adults. Unlike adults, children can communicate better with relatively little lexicon because their utterances are shorter and simpler in structure.

One more myth McLaughlin (1992) that expresses disapprobation for is that 'the younger the child, the more skilled in acquiring a second language'. He claims that younger children are not developed sufficiently cognitively and have little experience. As a consequence, they are at disadvantage in L2 learning; their learning process is longer and more complicated.

The learning styles of children, adolescents and adults are different. According to Figueiredo and Silva (2008), the language learning of children is implemented via feeling and linguistic sense. They refer to the Affective Filter Hypothesis of Krashen. This hypothesis suggests that learners have "emotional barriers," which they bring to a language class. Those impediments - stress, frustration, anxiety, inhibition, self-confidence - may decrease learning. To foster the success of learners, teachers should create a favorable environment in which students are unafraid of making mistakes and taking risks. In Hyltenstam and Abrahamsson (2005), social factors like friendly environment, modification of input, and cooperation are said to facilitate the language acquisition of children.

Zhang (2009), Nikolov and Djigunovic et al. (2006) take into consideration several influential aspects related to the age factor. One of them is metalinguistic awareness, which is the ability to separate language symbols from the meaning system. The vertex of metalinguistic development is observed when a child begins to acquire reading skills that should be highly practiced in the early school years, approximately at the age of 6-7.

\section{Instructional Methods for Students of Different Age Categories}

Young and older learners differ in their experience, cognitive abilities, and maturity. Learners at different ages have different types of brain organization (Singleton, 2001). In Vygotsky's work, the inclusion of culture and 
society are most evident as elements that impact cognitive development, (Vygotsky, 1978). The influence of culture and society are essential to social development theory. Every higher mental function, according to Vygotsky (1978), should initially be filtrated through an external stage in the form of social occurrences. Afterwards, these mental functions, through the use of language, are combined into an individual's thinking. According to Barac and Bialystok (2011), this "dialectical discovery" is a constant process that becomes gradually more complicated as time goes by (p. 10). Hence, every higher function originates as an authentic interpersonal relationship among and between individuals.

Teachers should be aware of age-related factors, when preparing a lesson plan for a particular age category. The general assumption is that young learners who are literate enough in their L1 have an advantage in SLA. There are some external factors, however, that can influence learning both positively and negatively for any age category. For instance, motivation may result in great success in the language acquisition of older learners.

Learners differ not only by age because linguistic and cultural background influence their learning. McLaughlin (1992) confirmed this argument saying that two systems differentiate learners from each other. These are the individual system of language and the individual linguistic factor (code levels during the communication).

All in all, every age category benefits from interactions with both the physical world (watching TV, playing games) and the social environment (talking to peers, native speakers, or knowledgeable ones). Moss (2003) lists several circumstances in which interaction may be more beneficial. According to her, interaction should contain elements, which are just beyond the current level of learner, propose specific outcomes, center on a particular problem, focus on details, and force learners to engage in the conversation.

\subsection{Instructional Methods for Children}

As the framework for all development and learning, Vygotsky's work in 1986 used social interaction. In a 1996 study, Cole and Wertsch affirmed that according to Vygotsky, "the development of the mind is the interweaving of the human body's biological development and the appropriation of the material/ideal/cultural heritage that exists in the present to organize people with each other and the physical world" (p. 2). According to Vygotsky's theory (1978), everyone has an individual range of learning capacity that is entitled the Zone of Proximal Development (ZPD).

The Zone of Proximal Development is divided into two attainment levels: Level 1 is the present development level. It indicates what children are able to do without any help from other people. Level 2 is the potential development level. It indicates what the children are able to do with help of teachers or other people. Vygotsky described the gap between levels 1 and 2 (the present and potential development) as ZPD. The zone itself is measured by the distance between the level of potential, as ascertained through collaboration with more knowledgeable peers or through problem solving with the guidance of adults and the present developmental level, as ascertained by solving an independent problem (Galant, 1998). Vygotsky (1962) asserted that, with help from other, more knowledgeable people, a child could potentially gain knowledge already held by them. To fit a child's level of comprehension, the knowledge that the child can gain should be of an appropriate complexity. Anything that is very complex to learn for the children and not in their ZPD, is difficult to learn till a shift in their ZPD occurs. Children can continue to learn more complicated high-level materials when this shift occurs and, thus, they can achieve their potential (Ozfidan, Burlbaw, \& Kocabas, 2018).

Vygotsky's idea in 1978 was that the learning process rather than the product should be studied, and he dealt with how a person as a part of learning actively modifies or mediates the stimulus situation. Vygotsky's thoughts focused on what social tools are involved in children's solutions to problems and how they go about the process of problem solving. Vygotsky studied the collaboration of subjects with a problem-solving task to evaluate their development, but he was not essentially concerned with whether a correct solution was found. The fundamentals like using of abstractions, past experiences, symbols demonstrated different developmental levels. Furthermore, Vygotsky would constantly add extra challenging situations to a problem-solving task such a mixed language groups so as to comprehend more regarding the process of finding solutions (Driscoll, 2001).

In addition to Vygotsky's ideas on cognitive development, three foundations from Piaget's constructivism also call for attention addressing this subject. They are equilibration, interaction between subject and object, and progressive construction. According to Piaget, equilibration encompasses assimilation and accommodation (Elkind, 1976). Assimilation refers to people transforming the information that they absorb from their external environment and processing it within their existing way of thinking. According to Piaget, accommodation occurs when people adapt their own thinking to fit the incoming information. The process of equilibration drives the cognitive development of children. Piaget suggested that equilibration takes place in three phases (Elkind, 1976). 
In the first phase of equilibration, according to Wadsworth (1971), children are delighted at their mode of thought and thus are in the state of equilibrium. Afterward, the author also emphasized that children then realize the inadequacies of their existing way of thinking and are dissatisfied with it. In other words, they are in a state of disequilibration and experience cognitive conflict. Finally, children accept a more knowledgeable mode of thought that overcomes the inadequacies of the old one. In other word, they reach a more stable equilibrium (Carothers \& Parfitt, 2017; Ozfidan, Machtmes, \& Demir, 2014). For instance, toddlers of one to two years of age start to name objects that they see in their everyday life. If they have a dog, they would call other furry animals with four legs (such as a cat) dog. Although their parents correct them, they would keep calling a cat a dog until their parents repeat the word cat many times and they accept the new name for a cat, which can be viewed as the newly established equilibration.

This cognitive process depends on both external factors (or environment) and internal factors. According to Bringuier (1980), "Knowledge is an interaction between object and subject" (p. 19). An object is an external factor or environmental factor while subject refers to the child. A child constructs his/her knowledge from one stage of development to the next (Fava, Hull, \& Bortfeld, 2011). In other words, the more information to which a child is exposed, the more learning that takes place in a child's mind. To increase his knowledge, a child actively interacts with his environment, relates his limited knowledge to the new information, and then adapts his new knowledge to fit his old knowledge (Ozfidan \& Ugurlu, 2015; Woofter, 2019).

The salient point of cognitive development in children is progressive construction through laborious training. In this instance, progressive does not mean the evolution of human beings, but rather the formation stages of development. Training here is not passive learning, but the interactive construction of knowledge. In terms of language development, Piaget believes that language serves multiple functions that develop with age. At first, language is basically repetitive and echolalic (Piaget, Gruber, \& Voneche, 1977, p. 65). The child only repeats what he/she has heard or understood from the speech of others (i.e., most infants start with simple sounds, such as mama, dada, nana, etc.). Next, the child is more interested in his/her own linguistic productions and repeats words for the pleasure of talking (Faltis, 2014; Flavell, 1999). For example, toddlers often talk to themselves before sleeping and waking up. They can speak for a long time using sounds that cannot be recognized as the words that adults use in speech, but after some time they begin to use words that can be understood. It is still echolalia. Next, monologue occurs when the child talks to him/herself as though he/she were thinking aloud. A collective monologue is a soliloquy in which the child uses the presence of others as a mere stimulus for his or her own verbal productions (Flavell, 1999). Piaget suggests that all these needs for language come from children's egocentric need or nature. This fundamental vocal preparation is to get children ready for socialized speech, which serves other functions such as the exchange of information, criticisms, commands, requests, threats, and questions and answers (Elkind, 1976).

Piaget arranged the different types of conversation into a developmental sequence. The explanations given by one child to another are egocentric (Piaget, Gruber, \& Voneche, 1977). For example, four-year-old children like to raise their voices when their parents are talking to others because they perceive that speaking loudly can attract the attention of their parents and reinforce their existence. Children between 6 and 8 years of age often slowly move away from an egocentric world and toward a world shared with others by changing their conversation type. For example, they may take the position of somebody who does not know. The child does not attempt to adapt his/her explanation to the viewpoint of others, but instead tries to understand how others see the world. This cognitive development is called decentration. One characteristic of this stage is that, children tell a story in the correct order.

Egocentric speech, from 9 to 11 years of age, gives way to a form of conceptual and verbal syncretism characterized by a need for justification at any price (Piaget, Gruber, \& Voneche, 1977, p. 66). Children of this age often jump too quickly from premises to conclusions, according to Piaget. They attempt to link everything with everything. "The child in verbal syncretism tends to drop all the difficult words in a narration or a sentence and to link all the easy words with one another so that he can, afterwards, reinterpret the difficult words he missed in the first place" (Piaget, Gruber, \& Vonech, 1977, p. 66). Children treat verbal syncretism and conceptual syncretism separately. In the cognitive process of this stage, children need to learn to or practice justifying the confusion, correctly evaluate and understand the specific and concrete spheres, then juxtapose them, and then explain the association between them.

The period of childhood is not only a remarkable physical growth period but also it is a significant mental development period. According to Piaget, cognitive skills are interconnected with problem solving, memory, thinking, and cognition skills and they continue to grow throughout the childhood period. When it comes to childhood cognitive development, not mentioning the work of psychologists Piaget, Gruber, and Vonèche (1977) 
is impossible. They state that the cognitive development of a child's capacity to learn and solve problems also includes using some physical abilities. For instance, cognitive development occurs when a two-month-old baby learns by discovering his/her environment through the use of eyes or hands. Children are gifted with the skill of comprehending knowledge three times faster than adults (Vygotsky, 1978).

Learning is generally a complicated process that is developed step by step (Ozfidan et al., 2018). In a 1996 study, Lee affirmed that learning builds on inborn capacities that are genetically coded and inherited at birth. Human beings can rarely learn to their full-inborn capacity, and only those people can achieve rewards for their performance and learning. Children's flow of learning development grows through the stages of innate abilities, sensory and motor skills, cognitive abilities, and lastly results in the skill to integrate formal instruction (Lee, 1996). In brief, an innate ability is a person's inborn capacity. Sensory and motor skills are built on the foundation of inborn abilities, and cognitive abilities allow a person to process the sensory information that he/she collects. The instruction stage is the last and most diverse level of learning. For instance, formal instruction comprises academic subjects such as reading, writing, typing, algebra among others (Lee, 1996).

Great numbers of mainstream linguists claim that children are most advantageous learners. In a 2014 study, however, Cook asserted that progress is not the same for students who acquire a language in natural environment and those who acquire a language in formal circumstances. Children are in developmental phase, which means, linguistic and social knowledge are acquired simultaneously.

Shakouri and Saligheh (2012) et al. claimed that children acquire a language in a natural way, which is considerably less anxious from that the way in which adolescents and adults acquire a language. They learn a language in a form of games, visual and aural stories, sketches. Instructional materials should be colorful and interesting. Ur (cited in Zhang, 2009) says: "the most effective combination in teaching is pictures and stories together" (p. 135). Teachers should praise students because maintenance of motivation is important at this stage.

During this period of time it is vital that children widen their vocabulary. In a study, Izura and Ellis (2002) affirmed that the lexicon learned during early years of language attainment, is recalled and uttered with lesser effort. They name some instructional activities, which are useful in new vocabulary learning: "object picture naming, word naming or reading aloud, visual lexicon decision, and auditory lexical decision" (p. 245). Thus, children benefit from sensorimotor activities and implicit mechanism.

The general belief is that children practice aimless repetition and imitation that make them rote-learners. Children greatly benefit from an environment in which the target language is spoken. Nikolov and Djigunovic (2006) concluded, that "classroom instruction providing children with opportunities similar to 'natural' SLA are appropriate in FL contexts" (p. 242).

According to Torras, Tragant, and Garcia (cited in Munoz, 2010), the process of child's language acquisition resembles the way in which sponges absorb water. Children learn new knowledge easily, and the younger they are, the stronger this ability is. The dominant source of knowledge is parents, caregivers, teachers, peers, people in surroundings, and mass media (as films and cartoons). Kerswill (1996) asserts that by the age of 6 or 7 children develop phonological features almost fully, and all of the significant rules are internalized by this time.

Munoz (2010) holds the position that younger students outperform older ones in morphosyntax and in pronunciation skills. Older learners, however, outperform younger in natural setting and short timing periods. Munoz remarked that young learners are slow in the beginning of learning but show high achievements in the long term.

\subsection{Instructional Methods for Adolescents and Adults}

The most influential characteristic of older learners is cognitive maturity. By virtue of cognition, they outperform younger learners, with the exception of pronunciation. Munoz et al. (2010) claimed that adolescents and adults benefit from formal settings with clear instructions and measurement tests. As Munoz emphasizes, school instruction corresponds to their capabilities in greater extent than to the capabilities of younger learners. Older learners acquire grammar in an intentional way, preferably with clear instructions. They benefit from deductive grammar teaching, in which explicit rules and examples on their use are demonstrated.

\subsubsection{Adolescents}

Figueiredo and Silva (2008) said that maturation, or neurocognitive development, and affective filters the language learning of adolescents. Johnstone (as cited in Shakouri \& Saligheh, 2012) listed some advantages of LL at the age of 10 and above. He says that those 10 and above are experienced enough to understand and produce a conversation, have practice in learning methods, and have a reason for learning L2. Zhang (2009) asserts that adolescents "are good at imitation and reminiscence" (p. 134). Thus, methods like repetition drills 
and dialogue memorizations may be profitable at this stage. He also concluded that adolescents like to feel the authority of a teacher. Taking this statement into consideration, teachers should serve the roles of lecturer, supporter, guide and director for all behaviors. As for methods, researchers point out that adolescents may feel rather anxious in public activities like role-playing.

\subsubsection{Adults}

A broad assumption is that adults have different purposes for learning a language. In most cases, their motivation is instrumental, which is characterized by willingness to learn a language to get a job, enroll in a university, or raise qualifications. In this instance, language teaching instruction should include working, or practical, knowledge of a target language. Thereby, adult learners would be able to satisfy their needs, especially in terms of academic purposes that include an understanding of relevant materials widespread on Internet. Smith and Strong (2002) supported the utilization innovative teaching in the adult classroom. They say that webquests, podcasts, blogs and broadcasts are stimulating and enjoyable. Some researchers believe that adults benefit from computer-assisted language learning methods, especially in terms of pronunciation.

Zhang (2009) stated that "teaching adults is easier and less stressful" (p. 135). Because they take more responsibility and are more disciplined. However, some requirements exist for instructors who teach adult learners; these include the fact that adults need to feel accepted, secure and supported in the classroom. They feel better, when collaborating with each other. To foster cooperation, teacher should ask questions, elicit, and invite students to share experiences. Adult learners prefer a formal style of language learning like comparable analysis and analytical thinking.

The motivational factor is significant for adult learners. Singleton's study (2001) concluded that fascination with language and the desire to be understood by native speakers facilitates learning. In addition, adults benefit from a range of social contacts and mobility (Kerswill, 1996).

\subsection{Differences Between Younger and Older Learners}

Singleton (2001) stated that "children and adults may have fundamentally different processing mechanisms at their disposal" (p. 79). The greatest difference between adult and young learners is cognitive maturity. Adults can think abstractly, while children lack cognitive abilities like complex brain-based skills, which are indispensable for performing a complex task.

Linguists say that the language acquisition of children is obtained intuitively, or subconsciously. Conversely, the cognitive maturity of adults turns the natural way of acquisition into intellectual practice. Children are unaware of mistakes, while adults feel frustrated when using a language incorrectly or being misunderstood. As a result of their self-consciousness, they always analyze their language performance. In a study, Nikolov and Djigunovic (2006) concluded that language acquisition of children was characterized by memorization and that the LL process of older students was more rule-based and focused on the concept.

\section{Which Age Category Is the Best to Begin L2 Learning?}

As Stern claims (cited in Shakouri and Saligheh, 2012), every age category has advantages and disadvantages. Concerning the question about when a person should begin to learn a L2, Shakouri and Saligheh affirmed that was neither a time that was too late or too early. Nonetheless, they support the opinion that beginning early is more profitable because young learners acquire language through intuitive capacities.

Despite the various advantages of learning a language in childhood, young learners may mix their native language and target language, says Zhang (2009). Stefansson (2013) explained this saying that children can confuse two languages and are unable to differentiate them. Genesee suggests (as cited in Stefansson) that parents should tolerate children's mixture of L1 and L2 because eventually they will learn to distinguish between two languages themselves.

Some researchers have claimed that adolescents show the best results in language learning. Zhang (2009) agreed that they can learn quicker and outperform children and adults in syntax and listening skills. Their flexibility and simultaneous process of mature development facilitate learning. The disadvantage of adolescents is their tendency to disruptions and egocentrism states Zhang. He gives some advantages and disadvantages of language learning in adulthood. Adults are motivated, experienced, have both short-term and long-term memories and possess meta-language awareness and common sense. They outperform children and adolescents in writing and reading skills. As a drawback, communication skills are developed slowly because their L1 interferes with L2.

\section{Discussion and Conclusion}

The purpose of this study was to examine the age factor in Second Language Acquisition. Answers to questions 
of which age is the most successful for second language acquisition and which instructional methods are the most beneficial at a certain age were examined were sought. Also, the study included an overall review on influential factors in SLA, the Critical Period Hypothesis, and an analysis of common SLA assumptions.

The Critical Period Hypothesis is based on neurological changes. The hypothesis posits that a non-native accent cannot be obtained after puberty (Hyland, 2019). However, Critical Period Hypothesis has debatable aspects. Thus, despite the assumptions of the $\mathrm{CPH}, 1)$ some adult learners can achieve native-like proficiency, and 2) some early language learners may have a "foreign accent" (Spinner \& Gass, 2019, p. 345)

Although age plays a critical role in language learning, other factors such as motivation, the capabilities of a learner, sufficient exposure to target language, interaction with the physical world and social environment, time available for learning, socioeconomic status, and linguistic and cultural backgrounds are seen to be more influential in some instances. As a result, late starters may achieve great success in language learning, as well as early starters (K. Hyland \& F. Hyland, 2019).

This study suggests that language teaching-learning processes differ among children, adolescents and adults. These differences are primarily explained by the experience, cognitive abilities and maturity of learners. Children also can experience anxiety and have to expend great efforts in the learning process (Spinner \& Gass, 2019). Additionally, if language exposure is insufficient, a child's progress may decline.

The instructional approach that should be used for young children should resemble the informal, or natural, way of language acquisition. The greatest distinguishing feature of children is subconscious learning. In this stage, a teacher is a model who helps learners in creating good habits. A slow beginning followed by a high level of achievement in the end defines the learning progress of children (Hyland, 2019).

Many researchers believe that adolescents are the most successful language learners. However, their egocentrism and propensity to disruptions may prevent excellent results. Adolescents succeed in repetition and imitation instructional activities (Cook, 2012; Munoz, 2010).

One assumption among researchers is that teaching adults is easier because of purposeful learning. Nevertheless, a teacher's role is vital because teacher is the one who creates non-threating environment and lowers anxiety. Adult learners benefit from analytic-style strategies like analysis, rules learning, and the study of words and phrases. Older learners show a high level of success in the beginning of learning, but, eventually, they slow down (Slabakova et al., 2019).

All in all, children outperform the other two other age category learners in terms of pronunciation and morphosyntax. Adolescents outperform children and adults in syntax and listening skills, and adults excel in reading and writing (Barac \& Bialystok, 2011). Children benefit from sensorimotor instructional activities, while older learners are good at higher-cognitive processing. Language learning methods for adults are characterized by rule-based activities and conceptuality (Andrews, 2017).

This study reveals advantages and disadvantages of language learning of three age categories (Ersoy et al., 2019). The age factor in SLA has been debated for several decades, and researchers cannot give conclusive and definitive answers to the question of which age is the most successful for second language acquisition.

\section{Acknowledgements}

The researchers thank Texas A\&M University and Prince Sultan University's Applied Linguistics Research Lab [RL-CH-2019/6/9] for funding this research project.

\section{References}

Andrews, K. (2017). Culture, Curriculum, and Identity in Education [Book Review]. Journal of Ethnic and Cultural Studies, 4(2), 99-101.

Archila-Suerte, Zevin, J., Bunta, F., \& Hernandez, A. E. (2012). Age of acquisition and proficiency in a second language independently influence the perception of non-native speech. Bilingualism: Language and Cognition, 15(1), 190-201. https://doi.org/10.1017/S1366728911000125

Aydin, H., \& Ozfidan, B. (2014). Perceptions on Mother Tongue Based Multicultural and Bilingual Education in $\begin{array}{lllll}\text { Turkey. Multicultural Education Review } & \text { (MER), } & 6(1), & \text { 51-78. }\end{array}$ https://doi.org/10.1080/2005615X.2014.11102906

Barac, R., \& Bialystok, E. (2011). Cognitive development of bilingual children. Language Teaching, 44(1), 36-54. https://doi.org/10.1017/S0261444810000339

Bringuier, J. C. (1980). Conversations with Jean Piaget. Chicago, IL: University of Chicago Press. 
https://doi.org/10.1007/BF02694634

Carothers, D., \& Parfitt, C. (2017). Disability or Language Difference: How Do We Decide? American Journal of Qualitative Research, 1(1), 1-12.

Cole, M., \& Wertsch, J. (1996). Beyond the individual-social antimony in discussions of Piaget and Vygotsky. Human Development, 39, 250-256. https://doi.org/10.1159/000278475

Cook, V. (2012). Some key issues for SLA research. In L. Pedrazzini, \& A. Nava (Eds.), Learning and teaching English: Insights from research (pp. 39-68). Monza, Italy: Polimetrica International Scientific Publisher.

Driscoll, M. (2001). Psychology of Learning for Assessment (2nd ed.). Boston, MA: Allyn and Bacon.

Elkind, D. (1976). Child development and education: A Piagetian perspective. New York, NY: Oxford University Press.

Ersoy, E., Ogurlu, U., \& Aydin, H. (2019). Gifted students' and their parents' perceptions of decision-making processes: A Turkish case. A Quarterly Review of Education, 50(3), 403-421. https://doi.org/10.1007/s10780-019-09357-1

Faltis, C. (2014). Toward a Race Radical Vision of Bilingual Education for Kurdish Users in Turkey: A Commentary. Journal of Ethnic and Cultural Studies, 1(1), 1-5.

Fava, E., Hull, R., \& Bortfeld, H. (2011). Linking behavioral and neurophysiological indicators of perceptual tuning to language. Frontiers in Psychology, 2. https://doi.org/10.3389/fpsyg.2011.00174

Figueiredo, S., \& Silva, C. (2008). The psychosocial predisposition effects in second language learning: Motivational profile in Portuguese and Catalan samples. Porta Linguarum, 10, 7-20.

Flavell, J. H. (1999). Cognitive development: Children's knowledge about the mind. Annual Review of Psychology, 50, 21-45. https://doi.org/10.1146/annurev.psych.50.1.21

Galant, M. (1998). Vygotsky's cultural/cognitive theory of development. Educational Psychology. Portland, OR: Cortland College. Retrieved from http://facultyweb.cortland.edu/ ANDERSMD/VYG/VYG.HTML, MA

Gruber, H. E., \& Vonèche, J. (Eds.) (1977). The essential Piaget. New York, NY: Basic Books.

Heo, J., Han, S., Koch, C., \& Aydin, H. (2011). Piaget's egocentrism and language learning: Language Egocentrism (LE) and Language Differentiation (LD). Journal of Language Teaching and Research, 2(4), 733-739. https://doi.org/10.4304/j1tr.2.4.733-739

Hyland, K. (2019). Second language writing. Cambridge university press. https://doi.org/10.1017/9781108635547

Hyland, K., \& Hyland, F. (Eds.). (2019). Feedback in second language writing: Contexts and issues. Cambridge university press. https://doi.org/10.1017/9781108635547

Hyltenstam, K., \& Abrahamsson, N. (2005). Maturational constraints in SLA. In C. Doughty, \& M. H. Long (Eds.), The handbook of second language acquisition (pp. 539-589). Malden, MA: Blackwell Publishing.

Izura, C., \& Ellis, A. W. (2002). Age of acquisition effects in word recognition and production in first and second languages. Psicológica, 23, 245-281.

Kerswill, P. (1996). Children, adolescents, and language change. Language Variation and Change, 8(2), 177-202. https://doi.org/10.1017/S0954394500001137

Lee, P. (1996). Cognitive development in bilingual children: A case for bilingual instruction in early childhood

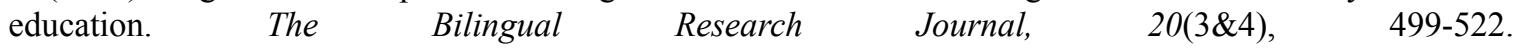
https://doi.org/10.1080/15235882.1996.10668641

Mclaughlin, B. (1992). Myths and misconceptions about second language learning: What every teacher needs to unlearn. National Center for Research on Cultural Diversity and Second Language Learning. University of California, Santa Cruz. Retrieved from https://files.eric.ed.gov/fulltext/ED352806.pdf

Moss, D. (2003). Second language acquisition in adults: From research to practice. National Center for ESL Literacy Education Lauren Ross-Feldman, Georgetown University. Retrieved from http://www.cal.org/caela/esl_resources/digests/SLA.html

Munoz, C. (2010). On how age affects foreign language learning. Advances in Research on Language Acquisition and Teaching: Selected Papers, Gala, University of Barcelona. Retrieved from http://www.enl.auth.gr/gala/14th/Papers/Invited\%20Speakers/Munoz.pdf 
Nikolov, M., \& Djigunovic, J. M. (2006). Recent research on age, second language acquisition, and early foreign language learning. Annual Review of Applied Linguistics, 26, 234-260. https://doi.org/10.1017/S0267190506000122

Ozfidan, B., \& Ugurlu, O. (2015). The idea of race and racial differences. Electronic International Journal of Education, Arts, and Science, 1(1), 85-98.

Ozfidan, B., Burblaw, L., \& Aydin, H. (2018). The minority languages dilemmas in Turkey: A critical approach to an emerging literature. Journal of Educational Issues, 4(1), 1-19. https://doi.org/10.5296/jei.v4i1.11498

Ozfidan, B., Burlbaw, L., \& Kocabas, S. (2018). Investigating attitudes towards a bilingual education curriculum: A scale development study. Review of Research and Social Intervention, 62, 105-117.

Ozfidan, B., Machtmes, K., \& Demir, H. (2014). Socio-cultural factors in second language learning: A case study of adventurous adult language learners. European Journal of Education Research, 3(4), 185-191. https://doi.org/10.12973/eu-jer.3.4.185

Shakouri, N., \& Saligheh M. (2012). Revisiting age and gender influence in second language acquisition. Advances in English Linguistics, 1(1), 1-6.

Singleton, D. (2001). Age and second language acquisition. Annual Review of Applied Linguistics, 21, 77-89. https://doi.org/10.1017/S0267190501000058

Slabakova, R., Corbet, J., Domínguez, L., Dudley, A., \& Wallington, A. (Eds.). (2019). Explorations in Second Language Acquisition and Processing. Cambridge Scholars Publishing.

Smith, A. F. V., \& Strong, G. (2009). Adult language learners: Context and innovation. Annapolis Junction, MD: TESOL Press.

Spinner, P., \& Gass, S. M. (2019). Using judgments in second language acquisition research. Routledge. https://doi.org/10.4324/9781315463377

Stefansson, E. G. (2013). Second language acquisition: The effect of age and motivation. Retrieved from https://www.scribd.com/document/383895260/AGE-AND-MOTIVATION-pdf

Ugurlu, O., \& Ozfidan, B. (2015). A Refugee Group's Mental Health and Social Care. Electronic International Journal of Education, Arts, and Science, 1(1), 99-114

Vygotsky, L. S. (1962). Thought and Language. Cambridge MA: MIT Press. https://doi.org/10.1037/11193-000

Vygotsky, L. S. (1978). Mind in society. Cambridge, MA: Harvard University Press.

Vygotsky, L. S. (1986). Thought and Language (A. Kozulin, Trans. \& Ed.). Cambridge, England: Cambridge University Press.

Wadsworth, B. J. (1971). Piaget's theory of cognitive development: An introduction for students of psychology and education. New York, NY: McKay.

Woofter, S. (2019). Book Review: Building Equity: Policies and Practices to Empower All Learners. American Journal of Qualitative Research, 3(1), 136-139. https://doi.org/10.29333/ajqr/5815

Zafar, S., \& Meenakshi, K. (2012). Individual Learner Differences and Second Language Acquisition: A Review. Journal of Language Teaching and Research, 3(4), 639-646. https://doi.org/10.4304/jltr.3.4.639-646

Zhang, C. (2009). A study of age influence in L2 acquisition. Asian Social Science, 5(5), 133-137. https://doi.org/10.5539/ass.v5n5p133

Ziglari, L., \& Ozfidan, B. (2016). Self-and Other-Repairs in Child-Adult Interaction: A Case Study of a Pair of Persian-Speaking Twins. International Journal of English Linguistics, 6(4), 52-59. https://doi.org/10.5539/ijel.v6n4p52

\section{Copyrights}

Copyright for this article is retained by the author(s), with first publication rights granted to the journal.

This is an open-access article distributed under the terms and conditions of the Creative Commons Attribution license (http://creativecommons.org/licenses/by/4.0/). 